ELORE (ISSN 1456-3010), vol. 18 - 2/2011.

Julkaisija: Suomen Kansantietouden Tutkijain Seura ry.

[http://www.elore.fi/arkisto/2_11/bjorkholm.pdf]

\title{
AKTUELLT
}

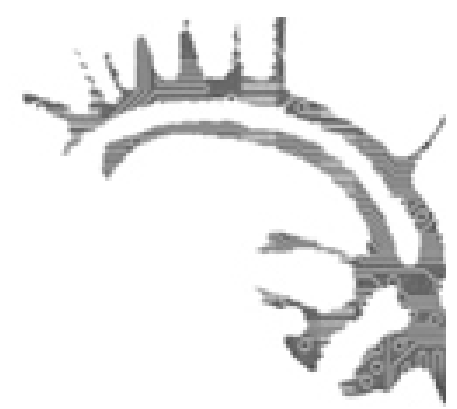

\section{IMMATERIELLT KULTURARV OCH FOLKMUSIK}

\author{
Johanna Björkholm
}

Lectio praecursoria vid Abo Akademi 10.6.2011

I dag inleds den finlandssvenska sång- och musikfesten "Ta i ton” med ca 3000 deltagare här i Åbo. I år är det också 120 år sedan den första finlandssvenska sångfesten arrangerades. Sångfesternas repertoar har av hävd till stor del bestått av arrangerade folkvisor, i år innehåller till exempel huvudfestens beställningsverk Var dag! arrangemang av folkvisorna "Ro ro till fiskeskär" och "Kling klang klockan slår", medan Finlands svenska damkörsförbunds konsert heter "Rock\&Folk".

I Svenskbygden N:o 31946 kan man under rubriken "En hälsning till sångaren i ledet" läsa:

Det är så mycket som hör samman med en allmän finlandssvensk musikfest. Där är ungdomsglädjen, glädjen att i den nordiska sommarens fagraste tid få sjunga tillsam mans med stamfränder från hela svenskbygden i Finland. [...] Där öppnar sig för oss den värld av skönhet och harmoni som musiken byggt upp och som ondskan aldrig kan förstöra. Där är kärleken till vårt svenska språk, viljan att vårda det kulturarv hängångna släktled anförtrott oss. Och där är kärleken till det land, för vars välgång intet offer är för stort (Svenskbygden 1946, 1).

Då, just efter krigsslutet, var det liksom här och nu aktuellt med en finlandssvensk sångfest, även om festernas kontexter är rejält olika.

Jag har skrivit en avhandling som heter Immateriellt kulturarv som begrepp och process. Vad är då ett immateriellt kulturarv och hur blir det till?

\section{IMMATERIELLT KULTURARV SOM BEGREPP}

Jag har undersökt begreppet immateriellt kulturarv genom att se på hur det används inom tre olika områden. Kulturarv diskuteras ofta inom kulturinstitutioner. Jag har 
Johanna Björkholm: Immateriellt kulturarv och folkmusik

undersökt såväl myndigheter som internationella organisationer och arkiv- och museisektorn. Jag har iakttagit vad man kan kalla insatsinriktade diskurser, som förmedlar att den egna verksamheten producerar kulturarv, eller med andra ord att den resulterar i kulturarvsstatus för vissa kulturkomponenter. Överlag kan man säga att flertalet av kulturinstitutionerna erkänner att kategorin immateriellt kulturarv existerar, men själva omfattar de den inte i sin verksamhet. Unescos program för immateriellt kulturarv utgör här ett klart undantag.

Begreppet kulturarv har även väckt intresse bland forskare under de senaste åren, men man diskuterar vanligen kulturarv i stort snarare än immateriellt kulturarv specifikt. Då begreppet kulturarv diskuteras i vetenskapliga sammanhang förekommer ett flertal diskurser. En av de mer tydligt uttalade är att kulturarv anses vara en kulturell konstruktion, inte någonting objektivt existerande. Vidare anses kulturarv iscensättas genom urval, och att deras stora värdeladdning och symbolvärde är avgörande. Det förekommer dock att forskare uppfattar allt kulturarv som immateriellt, så att kulturarvsstatus kan sägas ligga i betraktarens blick.

I finlandssvenska tidningar används begreppet kulturarv i mera vardagligt språkbruk. Här kommer enskilda individers synsätt fram. I vardagligt tal används kulturarv för att markera kulturkomponenter som anses betydelsefulla och som individen önskar bevara för framtiden - med eller utan officiella utnämningar. I tidningspressen omtalas både immateriella och materiella kulturkomponenter som kulturarv.

Immateriellt kulturarv som begrepp kan alltså betyda immateriella kulturkomponenter som har tillskrivits kulturarvsstatus. Faktum är dock att kulturarvsstatus och värdeladdning i sig alltid har immateriella aspekter, oberoende av om kulturkomponenterna är materiella eller immateriella. Kulturarv i stort handlar om de kulturkomponenter ur det förflutna som vi upplever vara viktiga och underförstått värda att bevara för framtiden.

Innebörden av begreppet kulturarv har förändrats över tid. På ett internationellt plan har begreppet immateriellt kulturarv blivit aktuellt sedan Unescos konvention för värn av immateriellt kulturarv trädde i kraft år 2006. Immateriell kultur kan nämligen inte bli världsarv, utan det finns en särskild, nyare konvention för immateriell kultur. Det inledande citatet från år 1946, där musik och språk diskuterades som kulturarv, visar dock att även immateriell kultur har omtalats som kulturarv betydligt tidigare än Unescos initiativ.

\section{IMMATERIELLT KULTURARV SOM PROCESS}

Immateriellt kulturarv som process riktar sökljuset mot det som händer då immateriella kulturkomponenter byter status och börjar uppfattas som kulturarv. I min avhandling har jag använt traditionell musik i Finlands svenskbygder för att undersöka en sådan kulturarvsprocess.

Den svenska museiforskaren Stefan Bohman har gjort en modell för hur det går till då materiella föremål inkluderas i museers samlingar och på så sätt tillskrivs kulturarvsstatus (Bohman 1997, 46 ff, 1999, 98 ff). Jag har utgått från hans idéer när jag 


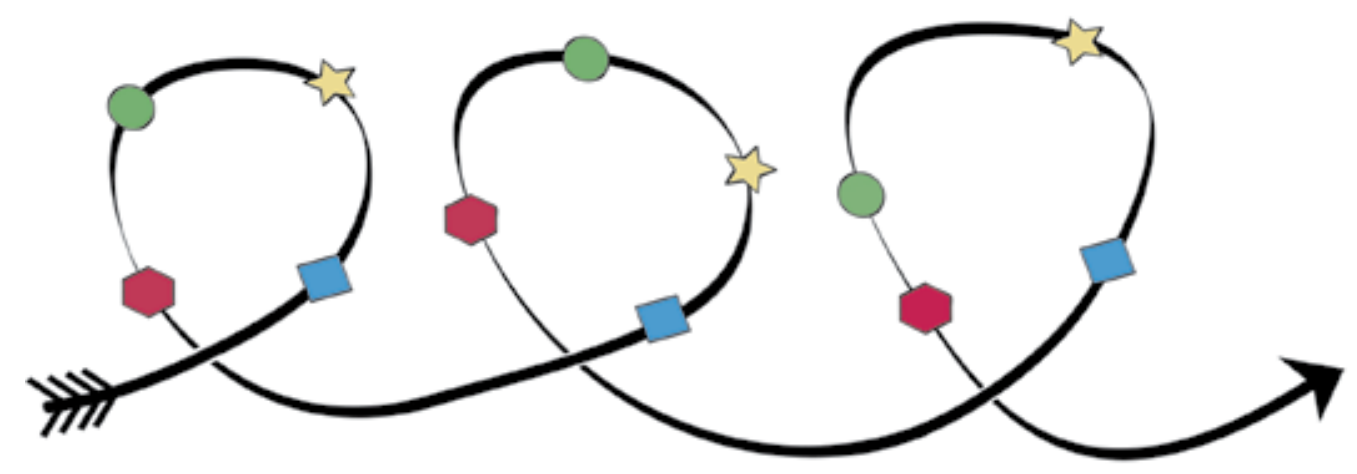

Uppställningen av kulturarvsprocessen i min omarbetade version.

har undersökt hur immateriellt kulturarv blir till, men jag har ändrat lite på modellen eftersom immateriell kultur inte är statisk på samma sätt som museiföremål.

Immateriell kultur, som till exempel sägenberättande, sång, seder, utövande av hantverk och traditionell kunskap är beroende av performans, det vill säga av att människor använder sin kropp för att framföra och fysiskt gestalta kulturkomponenter. I en performanssituation möjliggörs överföring, det vill säga att andra människor lär sig det som behövs för att de i sin tur ska kunna agera ut kulturkomponenterna. Utövarnas centrala position är alltså ett särdrag då det gäller immateriell kultur.

Förutom den ändrade bohmanska modellen har jag använt tankar som har att göra med performativitet för att undersöka processen som gör att vissa immateriella kulturkomponenter får kulturarvsstatus. Performativitet betyder att språket har en sådan makt att sättet som man talar eller agerar på påverkar hur vi uppfattar världen. I kulturarvsprocessen bygger både urval och värdeladdning på performativa processer. Då tillräckligt många människor talar om och agerar som om en kulturkomponent skulle ha specialstatus så kommer den också att framstå som ett kulturarv. Performativitet är en förenande länk mellan immateriellt kulturarv som begrepp och process.

Min omarbetade version av Bohmans modell för kulturarvsprocessen består av urvalsfas, värdetillskrivningsfas, avgränsningsfas och objektiveringsfas. Jag använder modellen för att undersöka den förändring som den traditionella musiken i Finlands svenskbygder har genomgått, till en genre med specifika värdeladdningar och symbolvärden, som betraktas som kulturarv av åtminstone delar av samhället. Jag använder texter som mitt källmaterial, och undersöker hur man har uttryckt sig om folkmusik.

Det är sedan länge känt att det förekom ett slags allmänna urvalskriterier för god folkkultur vid traditionsinsamlingarna: man krävde muntlig tradering, okänd upphovsman, variantbildning och ålderdomlighet, medan inget modernt inflytande fick förekomma. År 1960 skrev till exempel folkmusikinsamlaren Greta Dahl ström i ett brev till kollegan Alfhild Forslin om en insamlingsresa i Österbotten: 
Johanna Björkholm: Immateriellt kulturarv och folkmusik

Han [Lokalguiden] förargade mig ibland med att börja tralla någon polka eller vals och fråga efter den, just som spelmannen satt och letade i sitt minne efter något gammalt. Dock har jag 75 menuetter inspelade och 69 polskor. [Lokalguiden] hade ändå respekt för att O. A. [professor Otto Andersson] sagt att det skulle vara menuetter eller polskor i första rummet (Sibeliusmuseums arkiv, mapp Forslin).

Menuett är en ålderdomlig genre, dessutom är det unikt att den i Finlands svenskbygder förekommer i levande tradition. Det här är två orsaker till att menuetten gavs stort utrymme vid insamlingarna. Dessutom användes ett urvalskriterium där vikten av musikens värdighet framhölls. Man tycks ha tänkt sig att man genom att studera allmogens traditionella musik skulle kunna komma åt det förflutnas värdiga högreståndskultur, och då var den forna hovdansen menuett av stort intresse.

All musik som användes av allmogen ansågs dock inte vara lika intressant. Urvalet skedde enligt insamlarnas normer och sådan musik som inte passade dem ignorerades eller tillrättalades, som här i citatet genrerna polka och vals. Jag har med nutida terminologi betecknat den bortvalda musiken som skevheter, som sådant som inte passade insamlarnas uppfattningar om folkmusik.

Värdetillskrivningfasen innebar att den insamlade musiken användes i enlighet med vissa symbolvärden. Samtidigt framstod folkmusik även som ett verktyg som kunde användas för att förstärka andra önskvärda ideal. Den röda tråden i värdetillskrivningsfasen är att folkmusikens symbolvärde innebar anti-modernism och avståndstagande från industrialismen. Målet för användningen av folkmusik tycks ha varit att förmedla en tillrättalagd och romantiserad bild av det förflutna, och även av de svenskspråkiga finländarnas plats i detta förflutna.

År 1960 skrev till exempel Gunnel Ekholm under rubriken "Hur jag minns OllasAlfred" om Alfred Lindroos, föregångare inom hembygdsföreningsverksamheten på Pel linge, Borgå.

Ofta drömmer jag mig bort till Alfreds dagar, då Söderby var en förtjusande idyll av låga små stugor, då inget motorsmatter skar sönder sommarnattens stillhet, utan man i stället kunde höra sången från bygungan eller från någon fiskare stadd på hemfärd över viken (Ekholm 1960).

I Ekholms text användes folkmusik för att framhäva en nos talgisk och tillrättalagd bild av det förflutna. De kontexter som musiken placeras in i varierar dock i samklang med de rådande värderingarna i samhället. Under andra världskriget användes till exempel folkmusik för att framhäva betydelsen av styrka och uthållighet.

I avgränsningsfasen anpassades den traditionella musiken till insamlarnas värdesystem genom att den korrigerades enligt den borgerliga kulturens normer. I den här fasen tillrättalades musiken bland annat genom att den harmoniserades enligt konstmusikaliska normer, medan olämpliga sekvenser i texterna censurerades eller så skrevs helt nya texter till de traditionella melodierna. 
Ernst Lagus redigerade en av de tidigaste utgåvorna av folkvisor i Finlands svenskbygder, bandet Nyländska folkvisor inom samlingsverket Nyland, som utgavs 1887. Lagus skrev själv i förordet om sitt arbete med att censurera visorna:

Stundom har jag gjort smärre uteslutningar ur visorna, då de innehållit ord och skildringar, hvilka ur estetisk eller moralisk synpunkt måst undvikas. Arbetet är väl i främsta rummet utgifvet i vetenskapligt syfte; men då det utan tvifvel äfven kom mer i den stora allmänhetens händer, har jag ansett mig böra taga hänsyn äfven till dess åsikter angående anständighetens fordringar (Lagus 1887, VIII).

Dylika ingripanden tycks ha inspirerats av kulturevolutionistiska idéer, så att den borgerliga konstmusiken ansågs överlägsen, det vill säga längst hunnen i utvecklingen. Ingreppen i folkmusiken beskrevs därför som insatser för att "höja" eller "förbättra" den traditionella musiken. Samtidigt kanoniserades folkmusiken, bland annat på så sätt att vissa varianter framställdes som "de enda rätta". Uppfattningar om en korrekt version ledde till att variantbildningen upphörde, men de effekter som det här hade på traditionen diskuteras inte i mitt källmaterial.

I objektiveringsfasen etablerades folkmusik som ett självklart kulturarv. Objektiveringen skedde bland annat genom att folkmusik omtalades och behandlades som ett naturligt och värdefullt kulturarv.

Waldemar G. Lönnroos gav år 1962 ett exempel på hur folkmusikens status objektiverades, så att den framställdes som någonting man utan tvekan bör högakta och arbeta för att bevara:

Vårt spelmansgille har tagit till sin uppgift att uppteckna och samla låtar som eventuellt ännu spelas av gamla spelmän ute i bygderna. Dessa låtar är ett dyrbart kulturarv som bör bevaras åt kommande generationer (Lönnroos 1962, 3).

Vetenskapliggörande, vilket innebar att man inom vetenskaplig verksamhet intresserade sig för folkmusik, utgör även en del av den här fasen. Dessutom gjordes försök att organisera utövarna i olika organisationer, som arbetade utifrån uppfattningen att folkmusik var ett kulturarv väl värt att bevara för framtiden. Resultatet blev att genren folkmusik fick en specifik värdeladdning som gör att den ännu idag upplevs ha ett mervärde. Det faktum att folkmusikens symbolvärde förmedlar en mycket tillrättalagd bild av det förflutna gör dock att den idag riskerar att upplevas som förlegad och ofarlig eller till och med som tråkig.

Från min folkloristiska synvinkel är jag inte helt säker på vad som var målsättningen för folkmusikens kulturarvsprocess. Var det bevarande i form av vidmakthållen tradition som eftersträvades eller hade man snarare tänkt sig ett slags monument över allmogesamhällets musiktradition i det förflutna? Aktörerna inom kulturarvsprocessen diskuterade inte de här aspekterna. Så var de inte heller utövare som spelmän och sångare, utan studenter, lärare, journalister, vetenskapsmän och så vidare. Jag har kallat 
Johanna Björkholm: Immateriellt kulturarv och folkmusik

denna grupp för övertagare, eftersom de ofta nog inte såg folkmusiken som en del av "sin kultur". Faktum är att ett av resultaten av min undersökning är att utövarnas åsikter om sin musik har spelat en förvånansvärt liten roll i kulturarvsprocessen.

Genom en sådan här process väljs lämpliga kulturkomponenter ut och tillskrivs symbolvärde enligt rådande normer och förmodad nytta. Genom människors sätt att performativt agera och prata om dem kommer de att framstå som kulturarv. Det här betyder att kulturarv inte är naturgivna. Däremot kan vi genom att undersöka dem dels studera de normer som rådde då de tillskrevs kulturarvsstatus, dels undersöka hur statusförändringen har påverkat själva kulturkomponenterna.

\section{BETYDELSEN OCH EFFEKTERNA AV IMMATERIELLT KULTURARV}

Varför är då kunskap om immateriellt kulturarv viktig? Immateriellt kulturarv handlar om vad folk upplever som betydelsefullt och om hur man vill se sin plats i historien. Genom att undersöka immateriellt kulturarv kan man därför klargöra ideal och symbolvärden som påverkar hur vi tänker också i vår samtid.

I dagens läge ligger tyngdpunkten inom officiell kulturarvspolitik i Finland på materiell kultur. Även immateriell kultur upplevs, som jag har visat, som betydelsefull och omtalas som kulturarv. Bevarande av immateriell kultur kräver dock andra tillvägagångssätt i fall det är bevarande i form av vidmakthållen tradition som man önskar. Då räcker det inte med dokumentationer, som kan beskrivas som ögonblicksbilder av traditionen i form av framföranden av immateriell kultur.

Enligt mig kan man se en kulturarvsprocess som förklaringen till man den här helgen kan höra stora grupper av finlandssvenska sångare och musiker framföra arrangemang av traditionell musik här i Åbo. Genom kulturarvsprocessen har folkmusik etablerats som en genre med specifikt symbolvärde, och om man så vill, med en särskild betydelse för finlandssvenskarna. Processen pågår fortfarande, så att sättet som vi omtalar, skriver om och agerar kring de folkmusikaliska inslagen i sångfesten "Ta $\mathrm{i}$ ton” kommer framöver att påverka vårt förhållningssätt också till folkmusik i stort.

Björkholm, Johanna 2011: Immateriellt kulturarv som begrepp och process. Folkloristiska perspektiv på kulturarv i Finlands svenskbygder med folkmusik som exempel. Åbo: Åbo Akademis förlag.

[online] < http://www.doria.fi/bitstream/handle/10024/69672/bjorkholm_johanna. pdf?sequence $=1>$

\section{KÄLLOR OCH LITTERATUR}

BOHMAN, STEFAN 1997: Historia, museer och nationalism. Stockholm

BOHMAN, STEFAN 1999: Historia, museer och nationalism. Kulturarvet, museerna och forskningen. Stockholm

EKHOLM, GUNVOR 1960: Hur jag minns Ollas-Alfred. Borgåbladet 13.2.1960. 
Johanna Björkholm: Immateriellt kulturarv och folkmusik

Borgå

LAGUS, ERNST 1887: Nyland, band III. Nyländska folkvisor. Helsingfors

LÖNNROOS, G. WALD. 1962: Om gammaldans och spelmansmusik. Folkdansaren N:o 1 1962. [Helsingfors]

Sibeliusmuseums arkiv, mapp Forslin. Brev från Greta Dahlström till Alfhold Forslin daterat 26.7.1960.

Svenskbygden 1946: En hälsning till sångaren i ledet. Svenskbygden. N:o 31946.

Helsingfors

Filosofie doktor Johanna Björkholm forskar inom Svenska litteratursällskapets projekt Bitar av samma pussel? Intersektionella perspektiv på det svenska $i$ Finland och är t.f. universitetslärare i folkloristik vid Åbo Akademi. 